Abraham Trejo Terreros

Colegio de México, México

\title{
La relación México-Polonia en la mirada de la burocracia mexicana en el extranjero (1928-1935)
}

A través de los informes políticos elaborados por los representantes de México en Varsovia, el texto estudia las acciones de la burocracia mexicana en el extranjero para promover una imagen positiva del país latinoamericano. Sostengo que los reportes elaborados por estos agentes del Estado estuvieron informados por la propia experiencia mexicana en su camino hacia la centralización política y la formación de instituciones después de la Revolución de 1910. En un primer momento hablo del contexto en que México y Polonia establecieron relaciones diplomáticas. Ello sirve como telón de fondo de las siguientes dos secciones, donde abordo las formas en que los representantes mexicanos buscaron promover una imagen positiva de México en la Europa de entreguerras, y particularmente en Polonia, en dos rubros específicos: promoción de flujos migratorios y de una imagen favorable del país.

Palabras clave: política exterior, política interior, diplomacia de la no intervención en el periodo de entreguerras, emigración polaca al continente americano, imaginarios de México en el extranjero

By examining the political reports written by the representatives of Mexico in Warsaw, the article studies the actions of the Mexican bureaucracy abroad to promote a positive image of the Latin American country. I argue that the reports prepared by these agents of the State were informed by the Mexican experience itself on its way to political centralization and State formation after the Revolution of 1910. At first I address the context in which Mexico and Poland established diplomatic relations. Then I use that context as a backdrop to the following two sections, where I discuss the ways in which Mexican representatives sought to promote a positive image of Mexico in interwar Europe, and particularly in Poland, in two specific areas: promotion of migratory flows and a favourable image of the country.

Key words: foreign policy, domestic policy, non-intervention diplomacy in the interwar period, Polish emigration to the Americas, imaginary of Mexico abroad 


\section{Los inicios de una relación diplomática}

En mayo de 1926, la Secretaría de Relaciones Exteriores de México comunicó a su encargado de negocios en Praga el interés del Gobierno mexicano de establecer una representación diplomática permanente en Polonia. Para tal fin, le dio instrucciones de averiguar si las autoridades polacas estarían en disposición de nombrar un ministro o encargado de negocios en la capital mexicana. No fue hasta febrero de 1928 cuando el Gobierno polaco informó a su contraparte mexicana de que Zygmunt Merdinger sería nombrado Cónsul General en México; Merdinger también representaría a su país frente a Cuba y las Repúblicas centroamericanas. Sin embargo, Polonia no pudo cumplir su ofrecimiento de establecer una misión diplomática en México. Aun cuando en mayo de 1930 el ministro Rodolfo Nervo presentó sus cartas credenciales al Gobierno polaco, el país de Europa central no contaba con una representación en la Ciudad de México. El señor Filipowicz, que residía en Washington, fungía como representante de facto con el Gobierno mexicano. La legación polaca en Estados Unidos argumentó a diplomáticos mexicanos que la formalización de una representación en México se complicaba debido a la situación interna en Polonia. Por ello, los burócratas mexicanos prefirieron no poner en una situación «delicada y difícil» a Filipowicz exigiéndole «la reciprocidad absoluta» en cuanto a las representaciones diplomáticas. No fue hasta mediados de 1931 cuando se creó la Legación polaca con un ministro plenipotenciario en México (AHSRE 30-29-35, 1926).

La lectura de los informes elaborados por la burocracia mexicana en Varsovia permite subrayar la importancia de la política interna de Polonia para la definición de sus intereses y prioridades en política exterior. Algunos miembros de la burocracia mexicana en Europa atribuyeron las dificultades del Gobierno polaco para la formalización de relaciones a la falta de organización en el país de Europa central, por ser una nación que «acaba de iniciarse en la vida internacional» (AHSRE 30-2935, 1922). Los informes políticos elaborados por el ministro mexicano en Varsovia, Rodolfo Nervo, dan cuenta de las vicisitudes en la política interna polaca, la difícil situación financiera y también las tensiones de la Europa de entreguerras como causantes de dilemas del Gobierno polaco. Nervo hizo lecturas de la situación política interna e internacional de Polonia desde un lugar muy particular; es decir, en el contexto en que México buscó el reconocimiento diplomático de Estados Unidos y en el periodo de transición hacia la formación de instituciones políticas como forma privilegiada de dirimir las disputas políticas, y en contraste con la violencia iniciada con la Revolución en 1910.

La vida política de México y Polonia presentaba un paralelismo al momento en que buscaron establecer relaciones diplomáticas formales a nivel de legaciones, hacia finales de la década de los veinte: la presencia de una figura política decisiva para la toma de decisiones. Por un lado, el periodo conocido como el Maximato (19281934) hace referencia a la influencia que Plutarco Elías Calles tuvo sobre aquellos que ocuparon el Poder Ejecutivo durante este periodo, y en particular después del asesinato de Álvaro Obregón en julio de 1928. De ahí el dicho popular de la época de que el presidente en funciones vivía en el castillo de Chapultepec (lugar donde residían los poderes del Ejecutivo) pero que el que mandaba vivía enfrente. En Polonia, José Pilsudski había logrado consolidarse como el más influyente entre los líderes nacionales en el periodo de la posguerra mundial, cuando derrotó militarmente a los 
soviéticos, que habían asumido el control militar del territorio polaco al momento en que los alemanes se fueron replegando hacia el oeste. El grupo político que le era fiel a Pilsudski llevaba por nombre Belvedere, que era el palacio en donde este vivía y gobernaba. El liderazgo de facto del estadista polaco (1926-1935) llevó a que la burocracia mexicana en Varsovia se refiriera a Pilsudksi como el dictador disimulado del sistema político polaco. Así lo reseñó el encargado de negocios, Luciano Joublanc, en 1933: «El verdadero director y dueño de los destinos de Polonia es el Mariscal José Pilsudski, quien, entre bastidores, desde su palacio del Belvedere y su residencia de verano, dispone todo lo que se debe hacer, conferencia con los Embajadores y Ministros extranjeros y acuerda con los Ministros de Estado...» (AHSRE 3-4-11, 1933; Kieniewicz 173-185; Zamoyski 297-313).

Por su parte, durante el periodo de entreguerras los Gobiernos mexicanos emanados de la facción triunfante de la Revolución ejercieron una política exterior defensiva de carácter juridicista y promovieron la diversificación de las relaciones internacionales. Estos lineamientos seguían el objetivo de limitar las pretensiones intervencionistas de potencias extranjeras. Esta postura provenía de las tensas relaciones que con Estados Unidos tuvieron los Gobiernos mexicanos posteriores a la Revolución - Venustiano Carranza (1917-1920), Álvaro Obregón (1920-1924) y Plutarco Elías Calles (1924-1928) -, que vivieron de primera mano las presiones de Washington para lograr el reconocimiento diplomático. El Gobierno estadounidense lo condicionó a cambio de un arreglo formal que reconociera los intereses estadounidenses en México: desde las inversiones (notoriamente por parte de las empresas petroleras), pasando por la deuda que los Gobiernos mexicanos tenían con los banqueros y las indemnizaciones a particulares que vieron sus propiedades afectadas durante el conflicto armado (Vázquez, y Meyer 124-176)

La Doctrina Estrada (septiembre de 1930) fungió como la política del Estado mexicano para que no se condicionara el reconocimiento diplomático al cambio de régimen. México buscó ser observador de la Sociedad de Naciones en 1930. Cuando fue nombrado representante de México en la organización con sede en Ginebra, Isidro Fabela recibió instrucciones de promover la no intervención en asuntos internos y la defensa de cualquier país que sufriera agresiones externas (Mendoza 93-94). Bajo esta lupa la burocracia mexicana en Varsovia interpretó la vida política interna e internacional de Polonia al momento en que se instalaron las representaciones diplomáticas.

\section{Flujos migratorios hacia las Américas en el periodo de entreguerras}

Cuando los Gobiernos de México y Polonia estaban evaluando la posibilidad de establecer representaciones diplomáticas recíprocas, la burocracia mexicana en el exterior expresó a su contraparte polaca que los migrantes de aquel país de Europa central encontrarían oportunidades en México, principalmente si deseaban establecerse como agricultores. Incluso, el encargado de negocios de México en Praga argumentó que la decisión del Gobierno de Polonia de contar con una Misión en México se justificaba por el número de residentes polacos en México y por las posibilidades de incrementar las relaciones comerciales. Hacia 1925, el Ministerio de Asuntos 
Extranjeros de Polonia envió a México a un representante que elaboró un reporte sobre la situación de la colonia polaca en el país. El agente anotó que de un total de 2100 polacos en México, la mayoría residía en la capital del país y sus alrededores (734) y en estados al norte del país: Chihuahua (99), Coahuila (47), Zacatecas (24), San Luis Potosí (22), Nuevo León (20). Algunos de los reportes políticos elaborados por los representantes mexicanos en Varsovia durante el periodo aquí analizado dieron seguimiento a los flujos migratorios de polacos hacia las Américas. En estos se perciben intentos por identificar y regular los flujos de inmigración de polacos por territorio mexicano (Łepkowski 32-33).

El periodo de entreguerras fue denominado por un historiador polaco como el del nacimiento de la colonia polaca en México. El país contaba con la peculiaridad de la vecindad contigua a Estados Unidos, el principal polo de atracción de la inmigración polaca durante el periodo. Este mismo autor señala que la posibilidad de trasladarse a territorio estadounidense fue una constante y que los polacos lo intentaron hacer sin autorización de los Gobiernos mexicano y estadounidense. Łepkowski admite que estas características de la inmigración polaca a Estados Unidos son un motivo para dudar de las estadísticas de la presencia polaca en México. El historiador polaco concluye que la inmigración polaca en México se constituyó por el éxodo de personas del primer decenio de la Polonia restaurada, en su mayoría judíos, y provenientes de los territorios orientales del Estado polaco (Łepkowski 21-24).

En cuanto a la emigración de polacos, el periodo de entreguerras es también conocido como de la emigración dirigida, en tanto que los flujos migratorios fueron patrocinados e incluso organizados por el Estado polaco. La emigración fue percibida como un fenómeno positivo debido a que solucionaba tensiones internas, mediante el envío de ucranianos o judíos con la finalidad de regular el crecimiento demográfico de estas nacionalidades. Así, luego que se estabilizó la situación política en la década de los veinte, la Oficina de Emigración perteneciente al Ministerio de Trabajo y Asistencia Social se enfocó en atender y orientar la emigración. También se creó la Sociedad de Colonización de Varsovia con la finalidad de organizar el asentamiento polaco en América Latina, Francia y África (Dembcz, y Smolana 37-38). En particular, el servicio exterior mexicano reportó el traslado de polacos hacia Brasil. Este desplazamiento se logró porque la Sociedad de Colonización adquirió territorio en los estados de Paraná y Espíritu Santo, en Brasil, de cien mil y cincuenta mil hectáreas respectivamente. Los reportes elaborados en torno a estos traslados eran una manera de explorar las opciones que otros países otorgaban a los emigrantes polacos, frente a las que se hacían en México. La migración de polacos a Brasil fue alentada por la promoción que hicieron los Estados polaco y brasileño, la conexión marítima entre el puerto polaco de Gdynia con Río de Janeiro, y los esfuerzos de la Sociedad de Colonización para facilitar la migración temporal (AHSRE IV-132-34, 1930).

Sin embargo, al tiempo que el Estado polaco tomó estas acciones hacia la emigración, en el continente americano sucedieron políticas migratorias de restricción a la inmigración, y los informes de la burocracia mexicana en Polonia dieron cuenta de estos intentos por regular el ingreso de personas en los países del continente. Así sucedió en la coyuntura posterior a la crisis económica de 1929. En la entrevista que concedió Rodolfo Nervo al periódico polaco Le Messager polonais un día después de presentar sus cartas credenciales al presidente polaco, Ignacio Moscicki, el ministro 
mexicano afirmó que su Gobierno buscaba fomentar la inmigración polaca hacia México. También justificó que las medidas restrictivas hacia la migración laboral eran provisionales, y argumentó que eran medidas extraordinarias adoptadas debido a la repatriación de mexicanos desde Estados Unidos como consecuencia de la crisis financiera de 1929. En efecto, la Secretaría de Gobernación de México emitió un comunicado en abril de 1929 para prohibir temporalmente la entrada de inmigrantes extranjeros. La restricción migratoria fue adoptada en respuesta a «la crisis económica (que) atraviesa (México y que) ha dejado sin trabajo a considerable número de trabajadores mexicanos y en la miseria a sus familiares». También Estados Unidos redujo el número de inmigrantes polacos que podían ingresar a ese país: otorgó únicamente 650 visas anuales, y justificó tal decisión con los argumentos de la desocupación laboral y la crisis económica (AHSRE IV-395-51, 1931; Dembicz, y Smolana 17-40; Carrera de Velasco 57-72).

A pesar de las declaraciones de Nervo alentando el traslado de ciudadanos polacos a México, los reportes de la burocracia mexicana hablan de algunos inmigrantes polacos como no deseables para la nación mexicana. En un caso registrado a inicios de 1930 en Ciudad de México, un inmigrante polaco residente en la capital mexicana denunció ante Relaciones Exteriores que su esposa vivía con un «ruso» en el puerto de Veracruz, quien estaba a punto de ser expulsado de México por el delito de trata de blancas. Estas conclusiones apresuradas sobre perfiles de inmigrantes deseables e inconvenientes para la nación mexicana se superponían a la complejidad de englobar dentro de una misma categoría a los «emigrantes polacos». En efecto, un obstáculo para la identificación de la inmigración era la falta de uniformidad en el registro del lugar de origen. «Los judíos de los territorios orientales de Polonia hablaban frecuentemente el ruso (los llamados "lituanos"). En México, así como en los otros países de América Latina, habitualmente no se distinguía la nacionalidad entre los emigrantes de la Europa centro-oriental (Polonia, Bielorrusia, Ucrania, Rumania), tanto más que la mayoría de los emigrantes de esta parte del viejo continente era judía. Se les llamaba con el nombre común: los rusos o, más raras veces, los polacos» (AHSRE IV-117-20, 1930; Łepkowski 28) ${ }^{1}$. Se suman a la dificultad del estudio de la presencia polaca en América Latina los cambios de fronteras nacionales y la desaparición temporal de Polonia del mapa político mundial, y el hecho de que los emigrantes provenían de zonas con distintos referentes de identidad étnica (Dembicz, y Smolana 21-22).

En un viaje que realizó el polaco José Stankiewicz, señaló: «En todo el territorio de México no hay una colonia polaca pura... En total, el número de polacos no llega a 150 personas. El resto son emigrados judíos que poco después de su llegada a México olvidan el idioma polaco y generalmente toman la nacionalidad mexicana. El número de polacos en la capital de México no pasa de 20 personas que se comunican entre sí solo por azar, pues las circunstancias allí son muy difíciles» (AHSRE III1321-2, 1934). En efecto, de acuerdo con un informe de 1929, el cónsul polaco en México estimó que el 96 \% de los inmigrantes polacos en México eran judíos askenazíes. La comunidad judía en México mantenía relaciones con las organizaciones judías en Estados Unidos. Según el historiador Łepkowski, «la legación de la República de

1 AHSRE IV-117-20. «Consulado General de Polonia comunica expulsión de la esposa del señor Buchner, Wolf» Ciudad de México, 1930. 
Polonia intervino un par de veces en defensa de los judíos de esa nacionalidad con las autoridades mexicanas pero lo hizo "suavemente" por no querer dañar las relaciones con los mexicanos, quienes juzgaban negativamente el comportamiento de una parte de la colonia judía..., identificando a este gremio con todos los polacos» (Łepkowski 27 y 40).

\section{Estereotipos de México en la prensa polaca}

Cuando Rodolfo Nervo presentó sus cartas credenciales a Ignacio Moscicki, este preguntó al burócrata mexicano sobre la Revolución mexicana, pues tenía interés en conocer sus causas y procesos. No pasó mucho tiempo desde su llegada a Varsovia para que Nervo reportara a la Secretaría de Relaciones Exteriores en México acerca del «desconocimiento absoluto que existe en Polonia, de lo que es México y del papel que representa en la vida internacional» y de «la mala opinión que por desgracia existe entre el pueblo polaco con respecto a nuestra Patria». En ese reporte, Nervo reconocía que no existían malas intenciones hacia México y atribuía la mala imagen que se tenía en Polonia a «la atmósfera que nos hicieron hace ya unos siete $\mathrm{u}$ ocho años las agencias de noticias norteamericanas y las compañías cinematográficas, como resultado de los esfuerzos de nuestros gobiernos para poner en práctica las conquistas de la Revolución» (AHSRE III-1313-2. 14-26-12 (III), 1930, 1933)

En efecto, la industria cinematográfica de Hollywood difundió imágenes de un México degradado y bárbaro: «La industria cinematográfica de Hollywood se encargó de traducir en imágenes, reales o de ficción, las noticias que las agencias cablegráficas instalaron en las páginas de la prensa internacional. Escenas de la Revolución alimentaron un sinfín de películas, donde predominan mensajes profundamente racistas, transparentes en la certidumbre de la superioridad anglosajona norteamericana por sobre la inferioridad latina de los habitantes de México». La representación de los mexicanos como asesinos, borrachos y bandoleros fue motivo de preocupaciones de las legaciones mexicanas en el extranjero después que terminó el conflicto armado (Yankelevich 41).

Como medida para contrarrestar la mala imagen de México en Polonia, el encargado de negocios, Joublanc, propuso el intercambio de noticias positivas entre uno y otro país para su publicación en la prensa de circulación nacional. Aunque advirtió que este intercambio debía incluir «única y exclusivamente las [noticias] de carácter científico, literario, artístico, histórico, económico y comercial, y que por ningún motivo se aceptarán artículos o noticias de carácter político interno o exterior». La lógica detrás de restringir la difusión de asuntos políticos polacos era que en caso de publicar noticias «tendenciosas», México podía verse involucrado en tensiones diplomáticas con países vecinos a Polonia que eran amigos de México (AHSRE III1313-2, 1933).

Sin embargo, las imágenes de México en la prensa polaca como un país en total desorganización no sólo se nutrieron de las agencias internacionales; también encontraron espacio las narrativas de viajeros polacos por territorio mexicano. Si bien la estrategia de las representaciones mexicanas en el exterior fue de censurar la circulación de estas películas, por ejemplo, en los países de América Latina, o de llegar 
a acuerdos con los gobiernos para distribuir noticias con imágenes favorables del país, el caso de un artículo publicado en Krolewska Huta, en febrero de 1934, permite entrever la frustración de la burocracia mexicana por contrarrestar la imagen negativa del país.

El artículo aludido llevaba por título «México. Que desaparezcas, infierno sobre la tierra», y en este se referían estampas de Ciudad de México donde la corrupción y la pobreza eran el centro de atención del viajero polaco. De acuerdo con la experiencia de este observador, «la pobreza en México es espantosa» y los mexicanos pueden embriagarse, reñir y disparar ante los ojos de la policía (AHSRE III-13212,1934 ). La mirada del viajero polaco se enfocó a la confluencia de dos factores en Ciudad de México después que terminó el conflicto armado: la gran desproporción entre el aumento de la población y la falta de servicios públicos. La inmigración rural y la escasez de recursos hacían visible el hacinamiento y los riesgos a la salud y la moral con que se le asociaba. En la década de 1920, la población de Ciudad de México se incrementó en un $46 \%$, y los esfuerzos gubernamentales para abastecer la demanda de vivienda no fueron suficientes. De ahí que aumentara el establecimiento de casas en zonas contiguas a la ciudad, carentes de servicios, agua potable y entubada, desagüe, cañerías, pavimento, transporte, y luz eléctrica (cfr. Loyo Bravo 199-202).

Con todo, el encargado de negocios mexicano distinguió que aun cuando existían imágenes negativas sobre México en Polonia, ellas no eran tan virulentas o desproporcionadas como sucedía en otros países. En cambio, como sucedió en el caso de la situación de la Iglesia católica en México, atribuyó estos juicios a coyunturas políticas específicas. Sectores de la población polaca «creen que nuestro país es el que han visto retratado en las películas de la época de nuestros conflictos con el capitalismo norteamericano, aunque, naturalmente, no son pocos los que movidos por un catolicismo exagerado aprovechan estas pequeñas oportunidades de desprestigiar a México en represalia de las medidas que hemos tomado contra el clero» (AHSRE III-13132, 1933). El ministro se refería al conflicto armado, sucedido entre 1926 y 1929, entre grupos católicos, principalmente de la región central del país, y el aparato militar del Gobierno mexicano. La denominada Guerra Cristera se originó luego que Plutarco Elías Calles propuso aplicar lo estipulado en la Constitución de 1917: la prohibición de la participación política de las órdenes religiosas, la censura al culto público fuera de los templos y la restricción de poseer bienes raíces. Ello generó una confrontación armada que dejó alrededor de 250 mil personas muertas, entre rebeldes y fuerzas del Estado. Durante este periodo, los rebeldes católicos recibieron el apoyo tácito de la jerarquía católica. El acuerdo que dio fin parcial a los enfrentamientos armados sucedió por la intermediación del embajador estadounidense en México, Dwight Morrow, entre el Gobierno mexicano y el Vaticano (Meyer 363-392; Loyo Bravo 220-223). La Guerra Cristera también fue motivo del despliegue de imágenes sobre México y sus líderes en la prensa polaca. Un semanario católico publicó, por ejemplo, una fotografía desfigurada del general Calles, y se refirió a él como verdugo, judío, criminal, ridículo, usurero y payaso (AHSRE III-122-27 (I), 1935).

Pero más allá de la identificación de imágenes negativas acerca de México, la política exterior mexicana del periodo de entreguerras abrió canales de comunicación con diversos actores del sistema internacional. A la par de ejercer una política internacional juridicista, la apertura de nuevas legaciones permitió a la burocracia 
mexicana en el exterior practicar una diplomacia por diversos canales que se coordinaban con el interés del país de promover la no intervención en asuntos internos. Da cuenta de esta situación, la entrevista que el ministro mexicano tuvo con el representante del Vaticano en Varsovia, donde dialogaron sobre la situación de la Iglesia católica en México en tono de «cordialidad y cortesía». Este espacio le permitió al encargado de negocios Luciano Joublanc constatar el desconocimiento que prevalecía en el Vaticano de la situación mexicana de la posrevolución, en que «la Iglesia había procedido continuamente con una falta absoluta de tacto con respecto (al gobierno mexicano)». Declaraba, asimismo, que «no hay peor sistema para tratar de arreglar la situación entre nuestro Gobierno y el Vaticano, que las declaraciones violentas en la prensa, las amenazas y los actos de fuerza» (SRE III-1315-13, 1933).

\section{Consideraciones finales}

El artículo dio cuenta de cómo la situación interna en México y Polonia impulsó el establecimiento de relaciones diplomáticas, aunque, al mismo tiempo, los intereses de cada uno de los países condicionaron la falta de una estrecha colaboración en asuntos bilaterales. Por ejemplo, en estos primeros años de relaciones diplomáticas, no existió una coordinación a nivel gubernamental que materializara el traslado de polacos hacia México, como sí se concretó para conformar colonias de polacos en Brasil. Al contrario, la política mexicana reguló el ingreso de flujos migratorios bajo el argumento de privilegiar la mano de obra mexicana, que se consideraba que se veía afectada por la competencia que suponía la llegada de inmigrantes.

La diversificación que buscaron los Gobiernos mexicanos de la posrevolución trató de contrarrestar la mala imagen del país, que había sido difundida por las agencias de noticias y el cine estadounidenses. La práctica de buscar influir en la opinión pública de Polonia para terminar con los estereotipos del mexicano asesino, borracho y bandolero tenía sus límites, pues estas percepciones no solo se alimentaban por la difusión de imaginarios desde Estados Unidos. Si bien ese fue uno de los rubros en que la burocracia mexicana vio frustrados sus esfuerzos, la presencia de agentes del Estado mexicano en nuevas legaciones europeas contribuyó a la generación de informes que interpretaron la vida política europea en un momento en que México buscó diversificar sus relaciones exteriores.

\section{Referencias}

Archivo Histórico de la Secretaría de Relaciones Exteriores (AHSRE).

Archivo Histórico Diplomático Mexicano. Relaciones México Polonia 1921/1989. Cronología y documentos. México: Archivo Histórico Diplomático Mexicano, 1989.

Carrera de Velasco, Mercedes. Los mexicanos que devolvió la crisis: 1929-1932. México: Secretaría de Relaciones Exteriores, 1974.

Dembicz, Andrzej, y Smolana, Krzysztof. La presencia polaca en América Latina. Warszawa: Centro de Estudios Latinoamericanos, Universidad de Varsovia, 1993.

Kieniewicz, Jan. Historia de Polonia. México: FCE, 2001.

Łepkowski, Tadeusz. La inmigración polaca en México. Ciudad de México: Ciesas. Cuadernos de la casa chata, 1991. 
Loyo Bravo, Engracia. “El México revolucionario (1910-1940)". Historia mínima de la vida cotidiana en México, editado por Pablo Escalante Gonzalbo et. al. México: El Colegio de México, 2010: 185-244.

Mendoza, Carlos. Cien años de política exterior mexicana: De Francisco I. Madero a Enrique Peña Nieto. México: Instituto de Estudios Históricos de las Revoluciones de México, Grupo Editorial Cenzontle, 2014.

Meyer, Jean. De una revolución a la otra: México en la historia. Antología de textos. México: El Colegio de México, 2013.

Vazquez, Josefina, y Meyer, Lorenzo. México frente a Estados Unidos. Un ensayo histórico, 17762000. México: FCE, 2006.

Yankelevich, Pablo. "Asesinos, borrachos y bandoleros. El Estado mexicano ante la filmografía estadounidense en Latinoamérica (1919-1928)". Iberoamericana, 23,1 (73), 1999: 40-52.

Zamoyski, Adam. Poland. A history. London: William Collins, 2009. 